\title{
ÍNDICE DE VEGETAÇÃO COMO QUALIDADE AMBIENTAL URBANA: O CASO DAS PRAÇAS DA ZONA 03 DA CIDADE DE MARINGÁ, PARANÁ
}

\author{
Alex Sandre Campos Vieira ${ }^{1}$, Taís Müller ${ }^{2}$ \\ ${ }^{1}$ Mestrando em Geografia, Universidade Estadual de Maringá - UEM. Grupo de Estudos Multidisciplinares do Ambiente (GEMA). \\ alexscv2016@gmail.com \\ ${ }^{2}$ Mestranda em Geografia, Universidade Estadual de Maringá - UEM. Grupo de Estudos e Pesquisas "Sociedade, Ambiente e \\ Geotecnologias" (GEPAG). eng.taismuller@gmail.com
}

\begin{abstract}
RESUMO
O objetivo deste estudo visa discutir aspectos sobre indicadores de qualidade ambiental urbana em áreas verdes públicas no município de Maringá-PR em particular as praças do bairro zona 03, a partir de uma abordagem sobre a produção do espaço urbano e a influência da vegetação como fator de qualidade ambiental urbana do bairro zona 03. A metodologia utilizada partiu da elaboração de mapa de cobertura vegetal como indicador para a qualidade ambiental urbana da cidade, mas com recorte para o bairro em questão. Para produção desse mapa, utilizou-se plataforma online Google Earth Engine bem como para o tratamento das imagens utilizou-se o sistema de informação geográfica software QGis $3.6 \mathrm{com}$ o intuito de finalização dos mesmos e suas respectivas bases cartográficas. Os resultados deste estudo apontam que a cidade possui uma considerável qualidade ambiental urbana satisfatória, porém ainda requer melhorias em alguns dos pontos analisados como equipamentos urbanos visando satisfazer a função social e conservação e da qualidade do entorno.
\end{abstract}

PALAVRAS-CHAVE: Produção do espaço urbano, Áreas verdes urbanas, Qualidade ambiental urbana.

\section{INTRODUÇÃO}

Nas últimas décadas um dos principais desafios é tornar o espaço urbano equilibrado e sustentável. Devido a isto tem se intensificado os estudos sobre a relação entre cobertura vegetal nas metrópoles e os processos sociais e espaciais.

Nesta ótica, se observa que o planejamento urbano local deve estar voltado para a manutenção das áreas verdes, de forma que conserve valores naturais de um ecossistema, pois, estas apresentam benefícios ecossistêmicos como :decréscimo de ilhas de calor e de escoamento superficial da água (runoff), concentração de poluentes atmosféricos, redução de ruído, impacto de ventos, incidência solar em pavimentos e construções e como estoque de carbono (AMATO-LOURENÇO et al, 2016).

O ecossistema urbano está relacionado com a qualidade ambiental, que deve buscar o equilíbrio entre o sistema natural com o sistema antrópico por meio do planejamento urbano e ambiental adequados, que garantam a eliminação ou diminuição dos impactos ao meio ambiente, por meio da criação e manutenção de espaços livres com cobertura vegetal integrados com áreas de construção( PINA, 2011).

Quando se trata da qualidade ambiental, a vegetação assume papel relevante, uma vez que, no modo de produção capitalista, o homem ao estabelecer relação com o meio altera a dinâmica da inter-relação físico natural e interfere na qualidade da produção do espaço urbano (SOUZA; AMORIM, 2016).

A temperatura é um indicador de qualidade ambiental relacionado à cobertura vegetal em áreas urbanas, sendo que ambos estão associados ao bem-estar humano (funções de lazer). Devido a isto, o planejamento urbano deve estar voltado para evitar o declínio da qualidade de vida nas cidades (BARGOS; MATIAS, 2011).

Em face do exposto, o objetivo deste estudo visa discutir aspectos sobre indicadores de qualidade ambiental urbana em áreas verdes públicas no município de Maringá-PR, a partir de uma abordagem sobre a produção do espaço urbano e sua respectiva ocupação, em consonância as áreas verdes da cidade. 


\subsection{FUNCIONALIDADE E USOS DAS ÁREAS VERDES URBANAS}

Áreas verdes urbanas, como parques e campos de esportes, jardins, parques bem como bosques, representam um componente fundamental de qualquer ecossistema urbano. As árvores produzem oxigênio e ajudam a filtrar a poluição do ar prejudicial, incluindo o material particulado transportado pelo ar.

Amato-Lourenço (2016, p.4) definem área verde urbana como sendo:

Como uma rede de espaços verdes interconectados que conservam valores naturais de um ecossistema e que provêm benefícios às populações humanas. Pode ser composta por parques, florestas, praças, hortas comunitárias e outras formas de paisagens naturais públicas ou privadas. Nas cidades, incluem-se também a arborização urbana e os tetos verdes.

Os espaços verdes urbanos são considerados uma maneira apropriada de reduzir os efeitos das ilhas de calor urbanas e proporcionar conforto térmico do entorno e por conseguinte resfriar o espaço real.

As questões mais importantes no que diz respeito aos efeitos de resfriamento dos espaços verdes urbanos são a intensidade e a densidade do resfriamento, que podem desempenhar um papel importante para os projetistas e planejadores urbanos em lidar com as ilhas de calor urbanas. Este artigo analisa os últimos estudos que examinaram os efeitos de resfriamento dos espaços verdes urbanos nos últimos anos (ARAMA et al, 2019).

Quanto aos benefícios das áreas verdes urbanas pode-se destacar:

- Diminuição de temperatura que resulta em um decréscimo de ilhas de calor

- Diminuição de escoamento superficial da água (runoff)

- Concentração de poluentes atmosféricos

- Redução de ruído, impacto de ventos

- Incidência solar em pavimentos e construções (AMATO-LOURENÇO, 2016).

A vegetação possui ainda funções estéticas e recreativas. Propriedades próximas de áreas verdes ou possuindo vegetação tendem a possuir maior valor no mercado imobiliário. De acordo com o serviço florestal americano os benefícios das áreas verdes urbanas ou florestas urbanas proporcionam uma economia três vezes maior que o custo da manutenção destas áreas (AMATO-LOURENÇO, 2016).

\section{LOCALIZAÇÃO E CARACTERIZAÇÃO DA ÁREA DE ESTUDO}

Fundada em 1947, Maringá apresentou um rápido crescimento urbano acelerado, principalmente após a década de 70 , sendo o período de maior crescimento da cidade, atingindo pela primeira vez as imediações norte do Parque Municipal do Cinquentenário, fazendo com que surgissem os primeiros sinais de degradação ambiental, que foram observados na Unidade de Conservação (RUBIRA, 2016).

A zona 03, está situada na banda oriental de Maringá, (à direita da área central), na assim chamada Zona Sul. Sua dimensão total é de 70 alqueires $(1.683 .000,00 \mathrm{~m} 2)$, divididos em 70 quadras de tamanhos diferentes, retalhadas em 1.434 datas, sem contar o espaço destinado às indústrias, atrás da Avenida Mauá, considerado também do bairro e que irá influenciar de maneira decisiva o perfil do bairro. Integram o bairro 05 avenidas, 15 ruas e 05 praças, que são as seguintes: Praças: Regente Feijó, Praça Senador Abilon de Souza Naves, Praça Emiliano Perneta, Praça Rocha Pombo, Praça Fiori Progiante. (VILA OPERÁRIA, 2010). 


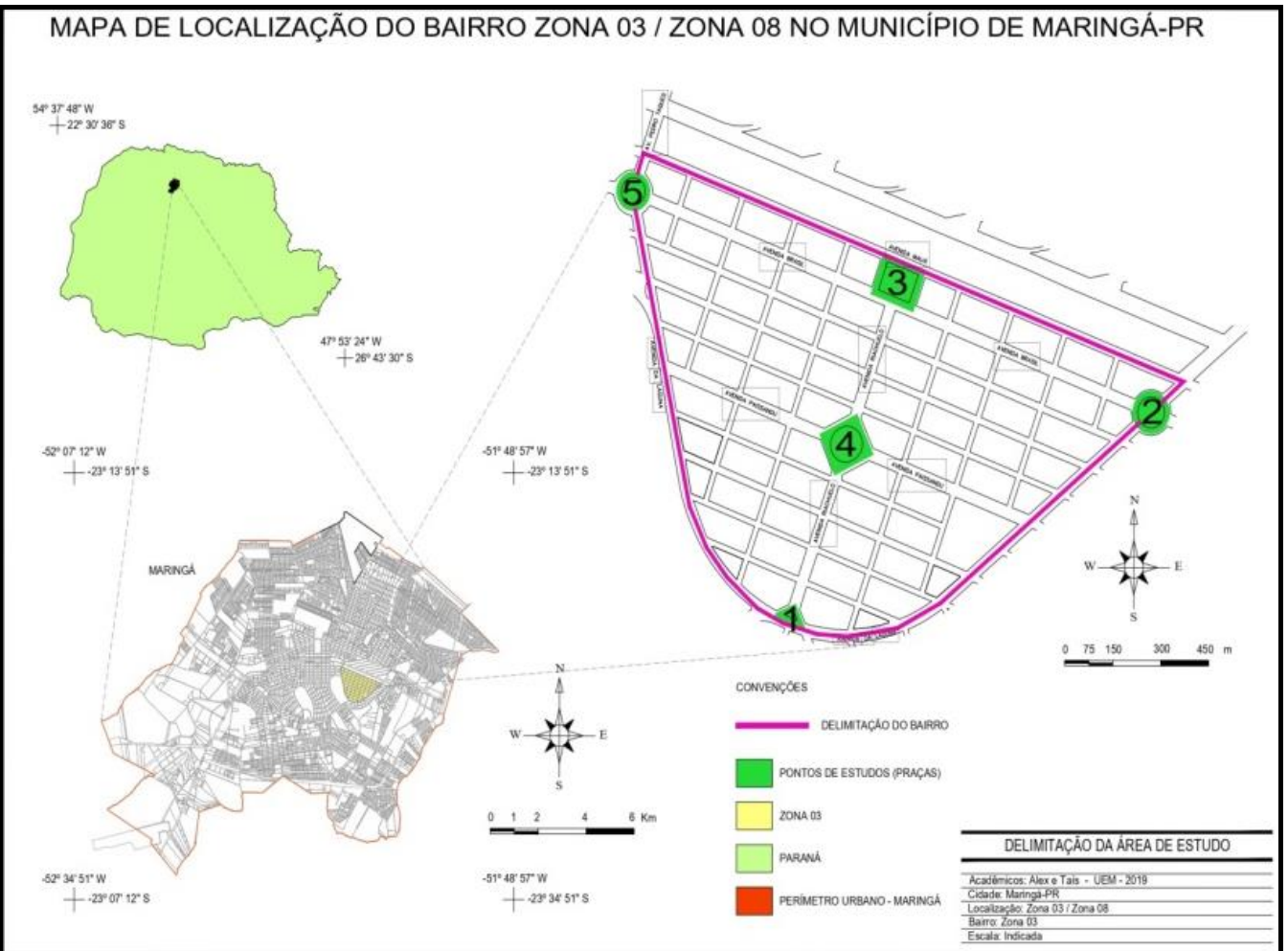

Figura 1: Localização do bairro zona 3 na cidade de Maringá PR

Fonte: Autores, 2019

\section{PROCEDIMENTOS METODOLÓGICOS}

Para a realização desta pesquisa foi adotado método de pesquisa qualitativo, o qual se desenvolveu a partir de duas etapas distintas complementares de coleta de dados: pesquisa bibliográfica e estudo prático de campo.

A pesquisa bibliográfica possibilita que o pesquisador esteja em contato o levantamento, seleção e documentação de bibliografias que já foram publicadas sobre o tema e que venha corroborar com conhecimentos sobre o tema e a elaboração do mapeamento e análise das características de cobertura vegetal (mediana - NDVI), temperatura da superfície (média) com a utilização do uso da plataforma Google Earth Engine para o tratamento dos dados extraídos de imagens de satélites Landsat 8, além da utilização do sistema de informação geográfica por meio do software Qgis 3.6 para a finalização dos mesmos. O resultado foi a elaboração do mapa de índice de vegetação.

No caso do estudo prático, este foi composto por uma seleção prévia "in loco" de algumas áreas verdes localizadas na zona 03 do município de Maringá-PR, a fim de caracterizar as praças selecionadas, no que diz respeito à sua infraestrutura, presença de vegetação, qualidade paisagística e aspectos urbanísticos em geral.

\section{RESULTADOS E DISCUSSÕES}

\subsection{PRAÇA FIORI PROGIANTE}

No estudo prático foi observado que neste espaço urbano a área verde cumpre função de permeabilização de água no solo. A vegetação existente contribui para manter o equilíbrio dos índices de temperatura, sendo um fator determinante para qualidade ambiental urbana local. 
Quanto ao aspecto de estrutura, a praça não dispõe de equipamentos púbicos (bancos, ATls e parques) e lixeiras, demonstrando que a área não cumpre sua função social.

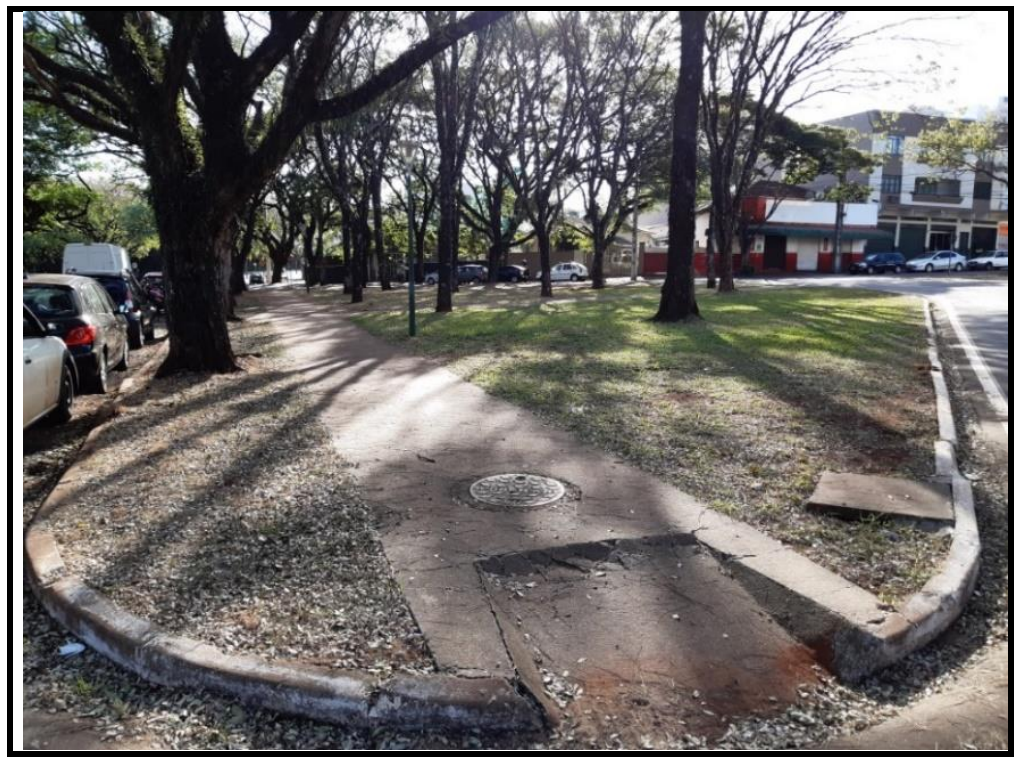

Figura 2: Praça 1: Fiori Progiante

Fonte: Autores, 2019

\subsection{PRAÇA ABILON DE SOUZA NAVES}

$\mathrm{Na}$ análise em campo, verificou-se que neste espaço livre urbano há vegetação e solo livre de impermeabilização, pois a permeabilidade dos solos em áreas verdes apresenta função ecológica, estética, econômica e sociais. A vegetação cumpre função potencial capaz de proporcionar um microclima distinto, embora não sendo na quantidade adequada as que existe, satisfaz para a contribuição quanto à luminosidade, temperatura e outros parâmetros associados ao bem-estar humano (BARGOS; MATIAS, 2011).

Em relação a função social, verificou-se que possui ciclovia, contudo não dispõe de equipamentos de uso público.

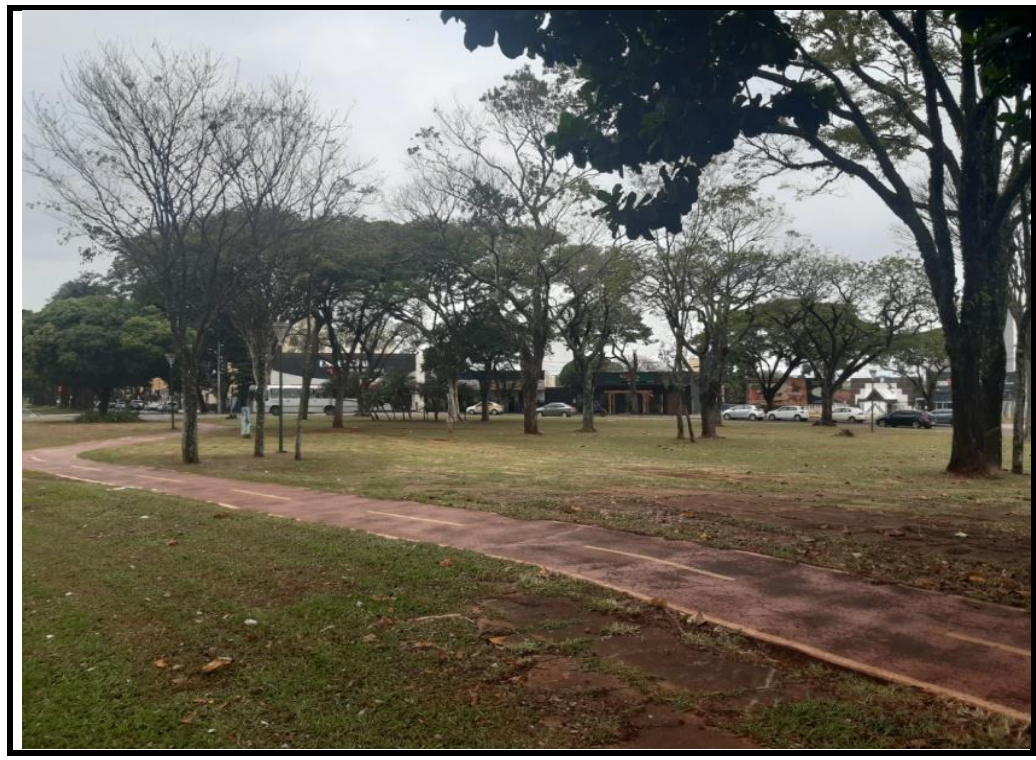

Figura 3: Praça 2: Abilon de Souza Naves

Fonte: Autores, 2019 


\subsection{PRAÇA EMILIANO PERNETA}

Diferentemente das demais praças, essa difere pela sua completa estrutura no que tange a função social com presença de lixeiras, equipamentos comunitários (ATI's), local para jogos de tabuleiro, bancos, praça bem cuidada, com estacionamento aos redores, área permeável, vegetação de grande porte que contribui para a manutenção da temperatura local. Além disso abriga a implantação de igreja e estrutura de apoio como sanitários.

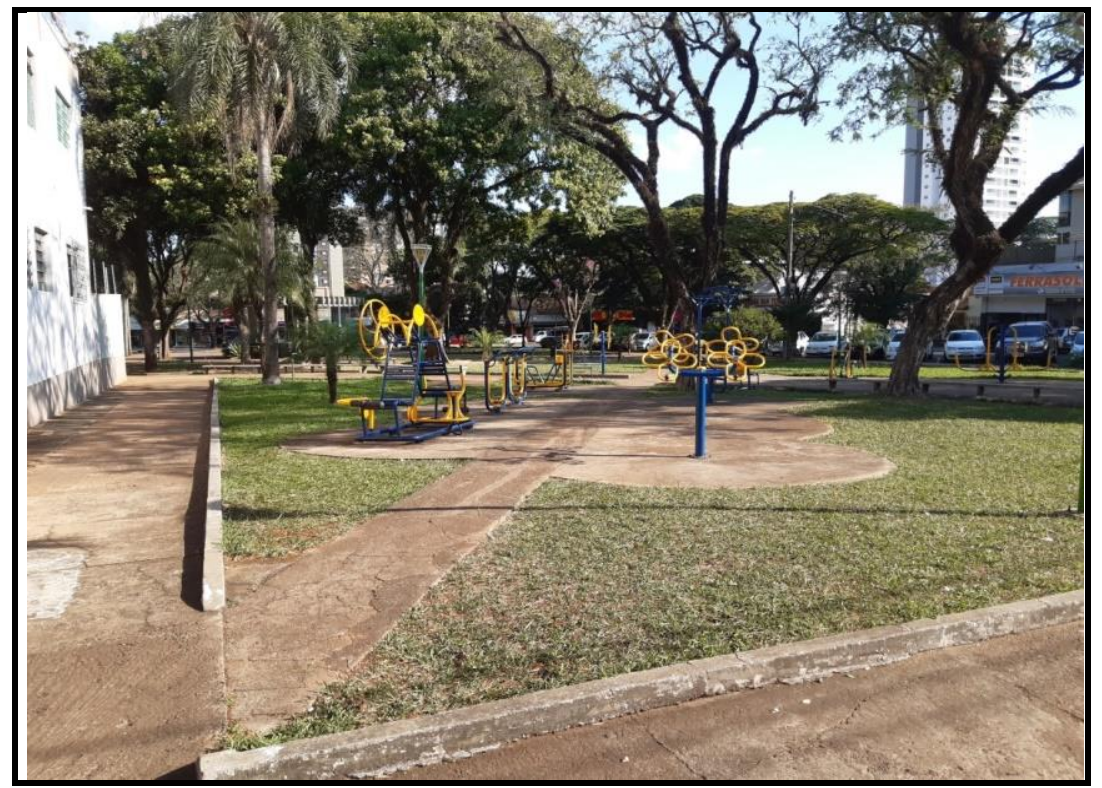

Figura 4: Praça 3: Emiliano Perneta

Fonte: Autores, 2019

\subsection{PRAÇA REGENTE FEIJÓ}

Área destinada ao uso público como espaço ocupado a centro esportivo, com piscina, área de jogos de tabuleiro, quadra poliesportiva, bancos, vegetação de grande porte e gramíneas satisfazendo em considerável área verde e temperatura bem como satisfazendo ao aspecto social.

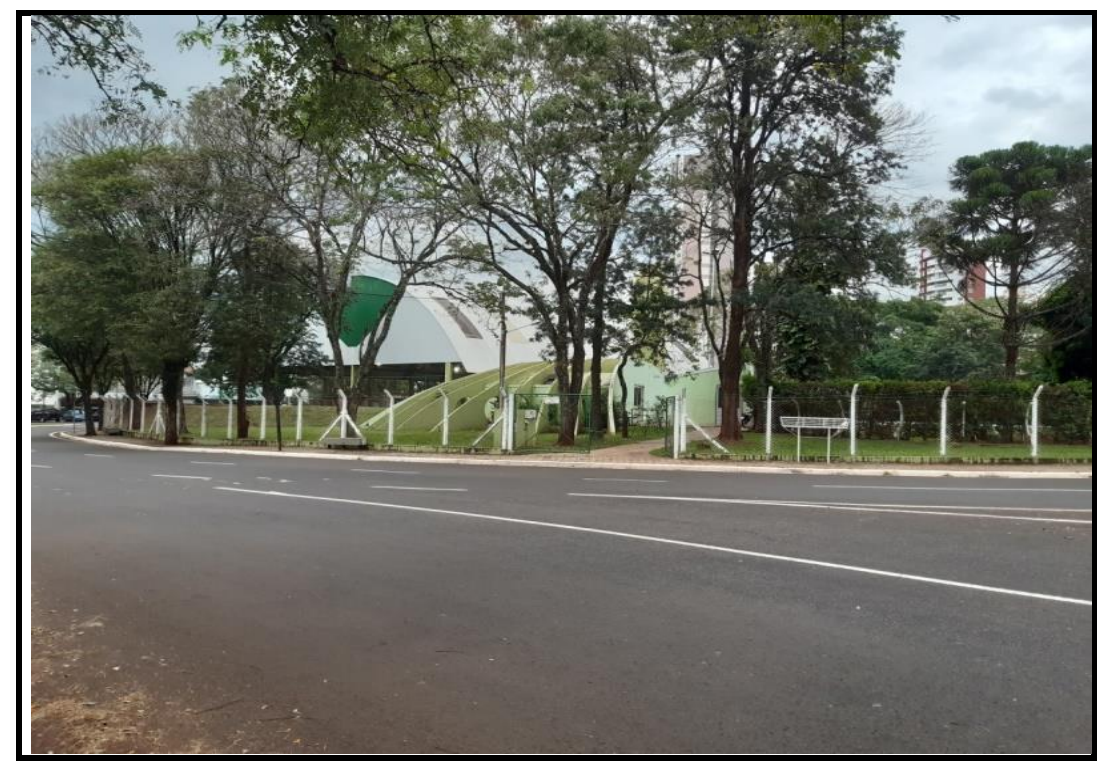

Figura 5: Praça 4: Regente Feijó

Fonte: Autores, 2019 


\subsection{PRAÇA ROCHA POMBO}

Praça com grande importância da cidade, pois divide a zona 01 da zona 03, tem um aspecto arquitetônico paisagístico interessante. Atualmente necessita de uma revitalização para valorização de si mesma e do entorno, pois em seu interior não dispõe de equipamentos públicos, apenas alguns bancos em mal estado de conservação, a vegetação é de grande porte e com presença de gramíneas.

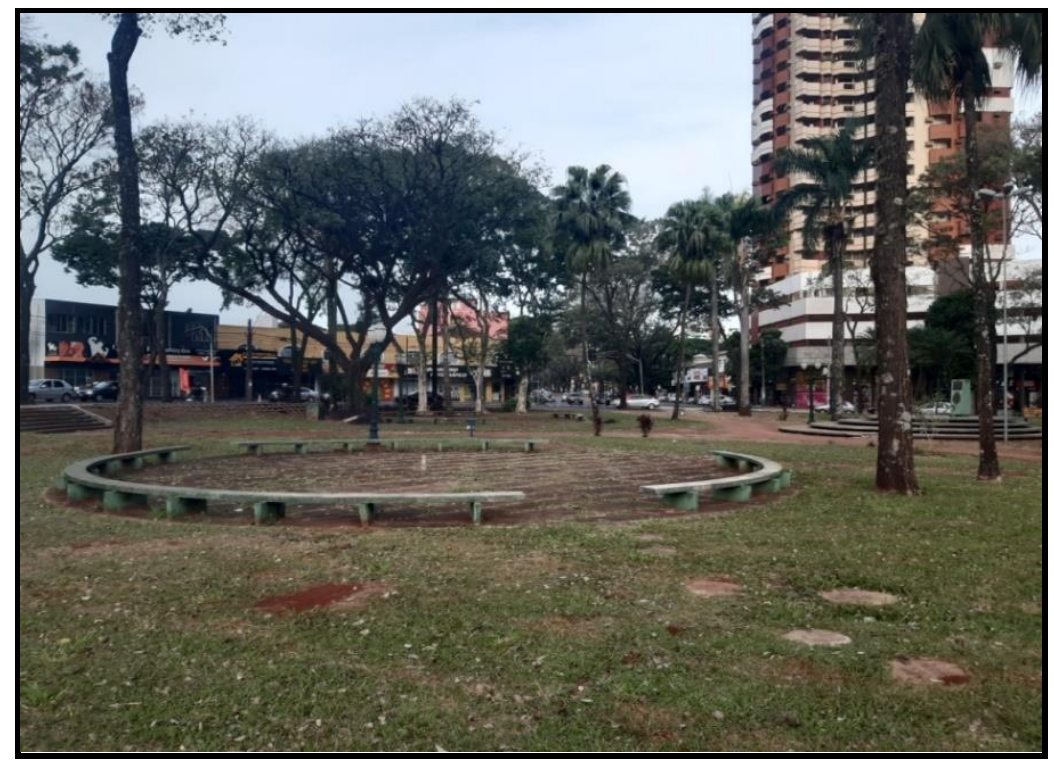

Figura 6: Praça 5: Rocha Pombo

Fonte: Autores, 2019

\section{6 ÍNDICE DE VEGETAÇÃO - NDVI}

O aspecto de índice de vegetação verifica a cobertura vegetal das áreas urbanas livres com apresentação de baixo índice de NDVI. A visualização da espacialidade das áreas verdes permitiu verificar que possui uma vegetação distribuída de forma isolada e dispersa.

De acordo com Rego et al (2012, p. 4):

O Normalized Difference Vegetation Index (NDVI) ou Índice de Vegetação da Diferença Normalizada, foi introduzido para produzir um índice de vegetação espectral que separa vegetação verde do brilho do solo. Este é o índice de vegetação mais comumente empregado, em estudos sobre vegetação que detém a habilidade para minimizar efeitos topográficos ao produzir uma escala linear de medida, possui a propriedade de variar entre $-1 \mathrm{a}+1$ (quanto mais próximo de 1 , maior a densidade de cobertura vegetal), o 0 representa valor aproximado para ausência de vegetação.

Lima e Freitas Filho (2015) explicam que por meio da utilização do NDVI, pode-se determinar a densidade de fitomassa foliar fotossinteticamente ativa por unidade de área (quanto maior este índice de vegetação, mais densa é a fitomassa verde). De acordo com estes autores à medida que aumenta a quantidade de vegetação verde aumenta a reflexão na banda do infravermelho próximo e, em equivalência, diminui a reflexão na banda do vermelho, fazendo com que o aumento da razão seja potencializado, destacando, assim, a vegetação. Com isso, tem-se caracterizado a área com maior concentração de vegetação. 


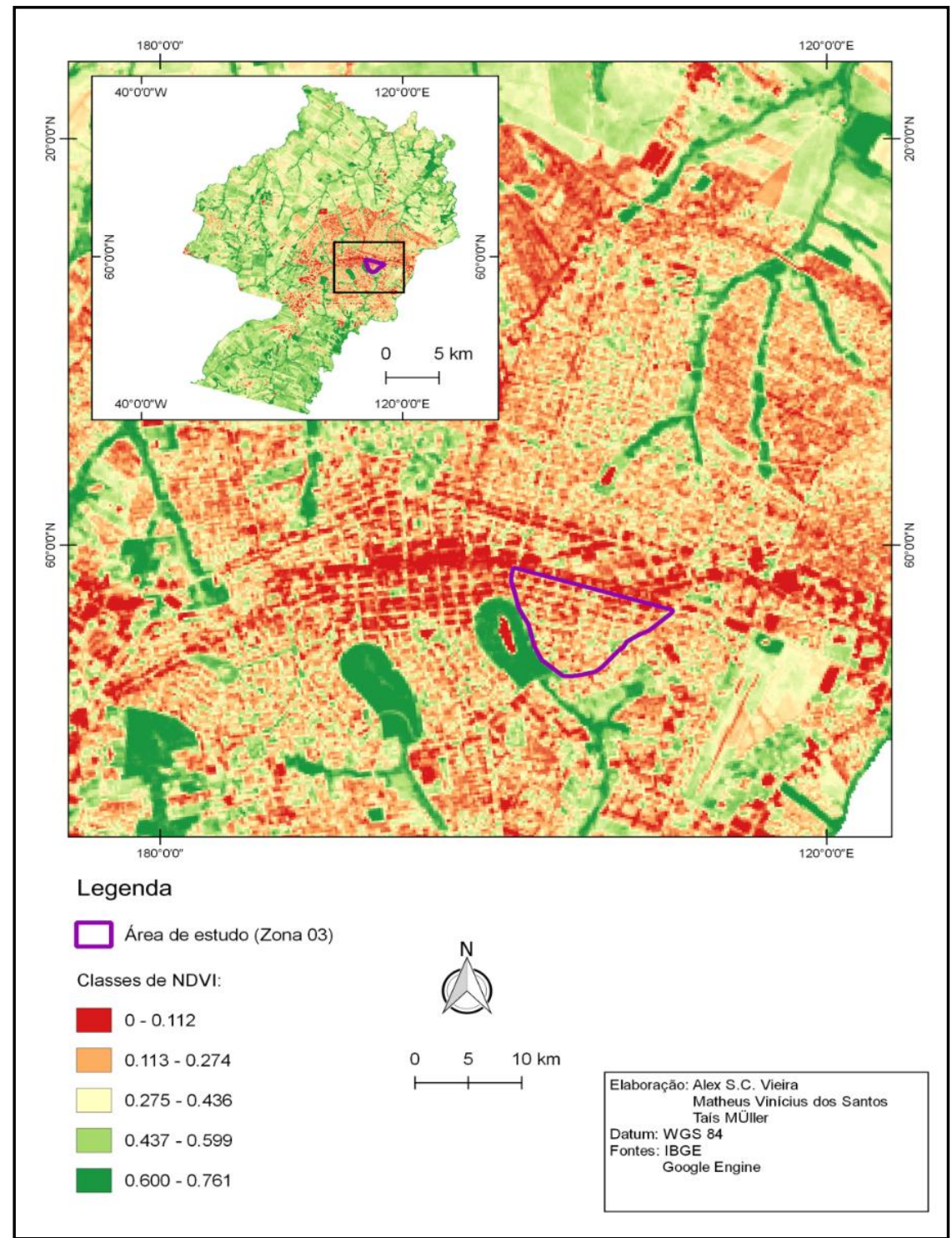

Figura 6: Praça 5: Rocha Pombo

Fonte: Autores, 2019

\section{CONSIDERAÇÕES FINAIS}

A partir da análise desse estudo foi possível discutir aspectos sobre indicadores de qualidade ambiental urbana em áreas verdes públicas no município de Maringá-PR, especificamente o bairro zona 3, a partir de uma abordagem sobre a produção do espaço urbano e sua respectiva ocupação tendo reflexo diretamente representado por meio do índice de vegetação.

Com relação ao objetivo de analisar as praças do bairro, em geral necessita atenção do poder público no aspecto de conservação e que, tampouco oferecem equipamentos urbanos que satisfaçam uma melhor qualidade de vida do local; outras abrange de maneira satisfatória com equipamento de lazer e uso público, estando localizadas em áreas centrais do bairro em questão. Contudo quanto a área verde, todas satisfazem de maneira satisfatória no que se refere a quantidade, mas necessita de investimentos quanto a qualidade, conservação e ou revitalização.

Por fim, por meio desse estudo e outros correlatos voltados ao planejamento urbano presentes nas universidades é possível que seja utilizado como subsídio para políticas públicas para análise dos indicadores de melhoria da qualidade. 


\section{REFERÊNCIAS}

AMATO-LOURENCO, Luís Fernando et al. Metrópoles, cobertura vegetal, áreas verdes e saúde. Estud. av., São Paulo, v. 30, n. 86, p. 113-130, Apr. 2016

ARAMA, Farshid. Urban green space cooling effect in cities. HELIYON. Volume 5, Issue 4, April 2019.

BARGOS, Danúbia Caporusso; MATIAS, Lindon Fonseca. Áreas verdes urbanas: um estudo de revisão e proposta conceitual. Soc. Bras. de Arborização Urbana REVSBAU, Piracicaba - SP, v.6, n.3, p.172-188, 2011.

LIMA, Denis Barbosa de; FREITAS FILHO, Manuel Rodrigues de. Análise do Índice de Vegetação como Subsídio ao Estudo de Degradação Ambiental: O Caso da Serra da Meruoca-Ceará. Geografia (Londrina) v. 24, n. 1. p.91 -105, jan/jun, 2015

PINA, José Hermano. A influência das áreas verdes urbanas na qualidade de vida : 0 caso dos parques do sabiá e Victório Sicquiorelli em Uberlândia Minas Gerais.MG. Universidade Federal de Uberlândia. Dissertação, 105 fls. Ueberlândia.MG, 2011.

RÊGO, Shirley Coutinho Alves. Análise comparativa dos índices de vegetação ndvi e savi no município de são domingos do Cariri-PB. REVISTA GEONORTE, Edição Especial, V.2, N.4, p.1217 - 1229, 2012.

RUBIRA, Felipe Gomes. Análise multitemporal da expansão urbana de Maringá-PR durante o período de 1947 a 2014 envolvendo o Parque Municipal do Cinquentenário e as principais áreas verdes do município Multitemporal. Caderno de Geografia, v.26, n.46, 2016

SOUZA, Mariana Cristina da Cunha; AMORIM, Margarete C. Costa Trindade. Qualidade ambiental em áreas verdes públicas na periferia de Presidente Prudente (SP): os exemplos dos bairros Humberto Salvador e Morada do Sol. Caminhos de Geografia Uberlândia v. 17, n. 57 Mar/2016 p. 59-73 Página 59

VILA OPERÁRIA. O Bairro. 2010. Disponível em:

http://www.vilaoperaria.com/historia/memoria-do-bairro/o-bairro.html>. Acesso em 05/08/2019. 